\title{
Sheep and food outputs and productivity from model farms in north-west Syria managed at different levels of intensity
}

\author{
E. F. Thomsont, F. A. Bahhady and T. L. Nordblom \\ International Centre for Agricultural Research in the Dry Areas (ICARDA), PO Box 5466, Aleppo, Syria
}

\section{Introduction}

Intensification of farm practices is often recommended as a way to increase output and profits of farms in developing countries. These practices are known to increase outputs when considered in isolation but they need to be assembled together into a whole-farm system which is then subjected to economic analysis. Two model farms and three experimental flocks were used in a 6year project to study the changes in sheep and food outputs, and productivity, under different levels of intensity at ICARDA's station in north-west Syria. The model farms were used to simulate the real farm environment on a research station and so allow close monitoring of all management activities which is more difficult to do on real farms. All the different components of a system can be assembled and evaluated together.

\section{Material and methods}

The medium (M) intensity farm of 14.3 ha supported an experimental flock (Ms) of 30 Awassi ewes, 10 replacement ewes and one ram, and the high $(\mathrm{H})$ intensity farm of 10.8 ha supported an experimental flock (Hs) of 35 ewes, 12 replacement ewes and one ram. Stocking rates were 2.9 and 4.4 sheep per arable ha on the $M$ and $H$ farms, respectively. The 9.9 ha of sparse natural pasture attached to each farm was stocked at 4.1 and 4.8 sheep per ha, respectively. A third experimental flock (Ls) had a similar size and flock composition as Ms but only had 19.8 ha natural grazing, giving a stocking rate of 2.1 sheep per ha. The $M$ farm had a barley/fallow and a wheat/ melon/lentil rotation whereas the $\mathrm{H}$ farm had a barley/vetch (for grazing) and a wheat/melon/ vetch (for hay) rotation. The Ls flock was 'poorly" managed, and the $M$ farm and Ms flock, and the $H$ farm and Hs flock, were managed according to traditional and semi-intensive practices, respectively. The $\mathrm{H}$ practices included better nutrition and health

t Present address: ICARDA, Brewery Road, PO Box 362, Quetta, Pakistan. care and crop rotations producing more food. This allowed the higher stocking rate on the $\mathrm{H}$ farm. Linear program (LP) models were developed to determine maximum sheep numbers, maximum output of sheep products and maximum profits for 10-ha arable farms with either the two- or threecourse rotations defined above, 10 -ha natural pasture and Ls, Ms or Hs flocks.

\section{Results}

The live weights of Ls, Ms and Hs ewes at mating were $40.9,43.6$ and $50.7 \mathrm{~kg}$, respectively, and were closely related to lambing rates of 79,86 and $98 \%$, respectively. Live weights of Ls, Ms and Hs ewes after lambing were $39.1,43.1$ and $51.4 \mathrm{~kg}$, respectively. These differences in live weights were reflected in annual mortality rates of 3.4, 0.9 and $0.7 \%$, respectively.

Prolificacy of ewes was similar across flocks. At 18 months of age, replacement Ls, Ms and Hs ewes weighed 38,40 and $44 \mathrm{~kg}$, had lambing rates of 0,3 and $13 \%$, and annual mortality rates of 0,6 and $0 \%$, respectively. Daily live-weight changes of lambs from Ls, Ms and Hs ewes were 186, 192 and $232 \mathrm{~g}$, and mortalities were 17, 6 and $7 \%$, respectively, up to 8 weeks of age.

Outputs from the Ls, Ms and Hs flocks were 5.7, 8.4 and $9.9 \mathrm{~kg}$ cull ewes per head, and $3.1,6.6$ and $8.7 \mathrm{~kg}$ lambs sold per head, respectively, and milk and wool outputs per head were $8.9,18.2$ and $25.3 \mathrm{~kg}$, and 1.2 , 1.4 and $1.6 \mathrm{~kg}$, respectively.

Annual supplementary food inputs to the Ls, Ms and Hs flocks were 89,113 and $178 \mathrm{~kg}$ per sheep, equivalent to 778,967 and $1698 \mathrm{MJ}$ metabolizable energy (ME) per sheep, respectively. These values represent proportionately $0.19,0.23$ and 0.40 of the estimated annual ME needs of a 'reference' Awassi ewe of $45 \mathrm{~kg}$ live weight yielding $110 \mathrm{~kg}$ milk.

Estimated ME productions on the $M$ and $H$ farms were 1393 and 1679 MJ per sheep, respectively, and 
after subtracting from this the ME supplied to each ewe but excluding straw production and consumption, the ME surplus on the two farms was 1803 and $1023 \mathrm{MJ} / \mathrm{ha}$, respectively.

LP analyses showed how replacing fallow land with a vetch crop increased numbers of sheep carried, sheep sales and farm profits but as farm intensity increased, the LP model selected less sheep per farm to maintain farm profits. A similar result was found when vetch replaced lentils in the three course rotations.

\section{Discussion}

The study indicated that intensifying sheep and crop enterprises resulted in substantial gains in physical outputs when expressed on a whole-flock basis. This would be attractive for the food importing countries of North Africa and West Asia which are striving to increase food security. Economic analysis using LP models showed that farmers would probably continue with their traditional management system. Indeed, the 'poor' management which is practised by many farmers in Syria appears to be the most appropriate since it has the lowest risk. Fine tuning of traditional systems, such as pre-mating feeding to increase lambing rate and well targeted health programmes should be the first step in improving the productivity of traditional systems which already rely heavily on the use of concentrates and crop residues.

Resolving technical constraints to increased animal production has been achieved with relative ease by researchers in developing countries using imported technologies. However, the research has usually been reductionistic. What is needed is more systemsorientated research, in which the components of systems are evaluated together. It allows the economics of the system to be evaluated. This may show that when the individual, supposedly profitable, components are assembled together, the overall system may no longer be profitable. The 'model flock' approach may be a useful method for national programmes to conduct component research, provided that the flocks can be made financially sustainable. 